\author{
Wilfred Druml \\ Barbara Metnitz \\ Erika Schaden \\ Peter Bauer \\ Philipp G. H. Metnitz
}

\section{Obesity and acute kidney injury: reply to Dr. Robert and coworkers}

Accepted: 17 July 2010

Published online: 24 September 2010

(C) Copyright jointly held by Springer and ESICM 2010

Dear Editor,

We thank Dr. Robert and colleagues

[1] for their comments on our study

on the impact of BMI on the evolu-

tion and prognosis of acute kidney

injury (AKI) [2]. We remind the

readers that in this study the impact of

$\mathrm{BMI}$ on the evolution AKI was cor-

rected for by several potential

confounders, such as age, severity of

disease, diabetes status, or

comorbidities.

Dr. Robert raises another possibility for a bias, i.e., the criteria for AKI diagnosis used in the Risk, Injury, Failure, Loss, and End-Stage Kidney
(RIFLE) classification. They discuss whether urinary output should-as required in both RIFLE and Acute Kidney Injury Network (AKIN) classifications-be corrected for by body weight which might introduce a bias in obese patients. Our diagnosis of AKI, however (as in most studies), was not based on urine criterion but on the creatinine criterion and the necessity of renal replacement therapy.

Dr. Robert also questions the validity of the creatinine criterion because obese persons also have a higher muscle mass and thus a higher creatinine formation. This fact-they argue - may result in an erroneous allocation of several subjects into the F category and also in an earlier initiation of renal replacement therapy in obese patients. This is certainly a point well taken; it is a problem which is inherent to currently used AKI classifications which all are based on serum creatinine. However, we only included patients in a really "failure" situation and the necessity of renal replacement therapy, a decision which rarely is based on creatinine concentration alone. A substantial impact of this potential bias on our results can largely be ruled out.

\section{References}

1. Robert R, Frat J-P, Hauet T (2010) Obesity and acute kidney injury: fact or artifact? Intensive Care Med. doi: 10.1007/s00134-010-2032-0

2. Druml W, Metnitz B, Schaden E, Bauer P, Metnitz PG (2010) Impact of body mass on incidence and prognosis of acute kidney injury requiring renal replacement therapy. Intensive Care Med 36:1221-1228

W. Druml $(\bowtie) \cdot$ B. Metnitz

E. Schaden - P. Bauer - P. G. H. Metnitz Department of Nephrology,

Vienna General Hospital, Währinger Gürtel 18-20, 1090 Vienna, Austria

e-mail: wilfred.druml@meduniwien.ac.at

Tel.: +43-1-404004503

Fax: +43-1-404004543 